\title{
Update on recommendations for the diagnosis and treatment of SARS-CoV-2 infection in children
}

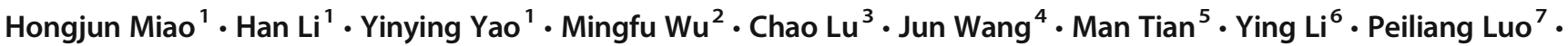 \\ Jianhui Gu ${ }^{8} \cdot$ Bin Yuan $^{9} \cdot$ Shouchuan Wang ${ }^{9} \cdot$ Xia Zhao $^{10}$. Weihua Gan ${ }^{11} \cdot$ Deyu Zhao ${ }^{5}$
}

Received: 26 March 2020 / Accepted: 29 June 2020 / Published online: 6 August 2020

(C) The Author(s) 2020

\begin{abstract}
Since the outbreak of novel coronavirus infection pneumonia in Wuhan City, China, in late 2019, such cases have been gradually reported in other parts of China and abroad. Children have become susceptible to severe acute respiratory syndrome coronavirus 2 (SARS-CoV-2) because of their immature immune function. As the outbreak has progressed, more cases of novel coronavirus infection/pneumonia in children have been reported. Compared with adults, the impact of SARS-CoV-2 infection in children is less severe, with a lower incidence and susceptibility in children, which results in fewer children being tested, thereby underestimating the actual number of infections. Therefore, strengthening the diagnosis of the disease is particularly important for children, and early and clear diagnosis can determine treatment strategies and reduce the harm caused by the disease to children. According to the Novel Coronavirus Infection Pneumonia Diagnosis and Treatment Standards (trial version 7) issued by National Health Committee and the latest diagnosis and treatment strategies for novel coronavirus infection pneumonia in children, this review summarizes current strategies on diagnosis and treatment of SARS-CoV-2 infection in children.
\end{abstract}

Keywords New coronavirus $\cdot$ Child $\cdot$ Diagnosis and treatment $\cdot$ Recommendation $\cdot$ Update

Hongjun Miao, Han Li and Yinying Yao contributed equally to this work.

Weihua Gan

weihuagan@njmu.edu.cn

Deyu Zhao

zhaodeyu988@126.com

1 Department of Emergency, Children's Hospital of Nanjing Medical University, Nanjing, China

2 Department of Pediatrics, The Affiliated Hospital of Yangzhou University, Yangzhou, China

3 Department of Pediatrics, The First Affiliated Hospital of Nanjing Medical University, Nanjing, China

4 Department of Pediatrics, The Affiliated Hospital of Xuzhou Medical University, Xuzhou, China

5 Department of Respiratory, Children's Hospital of Nanjing Medical University, Nanjing, China
6 Department of Emergency, Children's Hospital Affiliated to Suzhou University, Suzhou, China

7 Department of Pediatrics, The First People's Hospital of Lianyungang, Lianyungang, China

8 Department of Pediatrics, The Affiliated Hospital of Nantong University, Nantong, China

9 Department of Pediatrics, The Affiliated Hospital of Nanjing University of Traditional Chinese Medical, Nanjing,, China

10 Department of Pediatrics, The First Clinical Medical College of Nanjing University of Traditional Chinese Medical, Nanjing, China

11 Department of Pediatrics, The Second Affiliated Hospital of Nanjing Medical University, Nanjing, China 


\section{Epidemiological characteristics of SARS-CoV-2 infection}

\section{Infection sources}

Patients are the main source of infection. From the incubation period to the recovery period before the respiratory virus nucleic acid is negative for two consecutive times, they are infectious and highly infectious. Asymptomatic infections are common in pediatrics. The incubation period of SARS-CoV-2 infections ranges from 1 to 14 days, mostly ranging from 3 to 7 days. Currently, the longest incubation period was reported as 24 days $[1,2]$.

\section{Transmission route}

The main transmission ways of the virus are respiratory droplets and contact transmission, and the possibility of transmission by aerosol exists under conditions of prolonged exposure to high concentrations of aerosol in a relatively closed environment. The novel coronavirus can be isolated from feces and urine; therefore, attention should be paid to the aerosol or contact transmission caused by feces and urine to pollute the environment. Mother-to-child transmission and other transmission routes need to be further identified [3].

\section{Susceptible population and epidemic characteristics}

There are general susceptibilities in all groups, and children are no exception. Current reported data of infected populations revealed that the ages of those infected with the disease ranged from $36 \mathrm{~h}$ to 96 years, with no significant gender difference. There are less pediatric cases, and less severe, although some severe pediatric cases have been reported. In this outbreak, there are obvious features of clustering, and the number of imported cases or those transmitted by second-generation transmission is rapidly increasing and is highly contagious. Close family contact is the main mode of infection in children [4]. Deaths in children have been reported to date [5].

\section{Etiology and pathological mechanism}

After SARS-CoV-2 comes into contact with the human respiratory tract, the spike protein of the virus binds to the surface receptor of sensitive cells, angiotensin-converting enzyme 2 (ACE2), which mediates viral entry into type II alveolar epithelial cells to facilitate virus proliferation and spread. ACE2 is highly expressed on alveolar cells in Asian males [6]. Recently, it has been reported that the S protein of SARSCoV-2 binds to ACE2 with a higher affinity than SARS coronavirus, which might contribute to the rapid spread of COVID-19 [7]. Currently, it is unclear whether children's low susceptibility to SARS-CoV-2 is related to the development and function of ACE2. SARS-CoV-2 can destroy lymphocytes. Therefore, the absolute number of lymphocytes in peripheral blood in adults is significantly or progressively reduced, and the subsets of CD $4^{+}$and $\mathrm{CD} 8{ }^{+} \mathrm{T}$ cell subsets are all decreased. While the white blood cell count and absolute number of lymphocytes in children are mostly normal [8]. SARS-CoV-2 infection is also associated with an inflammatory cytokine storm, which is characterized by elevated levels of in various inflammatory factors. Serum fibrinous exudate and hyaline membrane formation are observed in the alveolar cavity; exudative cells consist mainly of monocytes and macrophages, and multinucleated giant cells are easily observed. Part of the epithelium of the bronchial mucosa in the lungs is shed, and the formation of mucus and mucus plugs in the cavity is visible. The lungs show varying degrees of consolidation, with a few manifestations of excessive alveolar inflation, alveolar septum rupture, or cyst cavity formation [3].

\section{Clinical manifestations}

At the onset of the disease, infected children mainly present with fever and cough, which might be accompanied by systemic symptoms, such as fatigue, myalgia, headache, dizziness, nausea, vomiting, abdominal pain, diarrhea, nasal congestion, runny nose, sneezing, and sore throat. Moreover, their thermal pattern is irregular. They could present with high, medium, or low fever, even no fever. Symptoms of some children and neonates are not typical, presenting with gastrointestinal symptoms, such as vomiting and diarrhea or only with mental weakness and shortness of breath. The current case analysis shows that in children, the duration of fever is mostly 1-2 days, with a maximum of 8 days. In the early phase of the disease, the total number of white blood cells in peripheral blood is normal or decreased, with a decreased lymphocyte count $[9,10]$. Dyspnea, cyanosis, and other symptoms can occur as the condition aggravates, usually after 1 week of the disease. The condition of some children might progress rapidly and could develop into respiratory failure that cannot be corrected by conventional oxygen (nasal catheter, mask) within 1-3 days, which indicates that the child is critically ill. In these severe cases, septic shock, irreversible metabolic acidosis, and bleeding and coagulation dysfunction may occur [11]. At the same time, children with other (i.e., comorbid) diseases (such as congenital heart, lung and airway diseases, malnutrition, and tumors, etc.) are vulnerable to infection with SARS-CoV-2; more specifically, "prone to severe illness." Older children might have similar forms as adults. Compared with adults, children with COVID-19 were mild symptoms, faster recovery, shorter detoxification time, and good prognosis $[12,13]$. Neonates, especially preterm infants, who are more likely to present with insidious and non-specific 
symptoms, need closer observation. According to the clinical characteristics of existing cases of infected children, they can be divided into the following clinical types:

\section{Asymptomatic infection}

The patient's SARS-CoV-2 nucleic acid test was positive, but there are no clinical symptoms.

\section{Mild type}

The main manifestation in these patients is acute upper respiratory infection. Pharyngeal hyperemia is observed on physical examination with no positive sign in the lungs.

\section{Ordinary type}

Symptoms include fever, cough, pharyngeal pain, nasal congestion, fatigue, headache, and myalgia. Some patients show signs of pneumonia on chest imaging; however, but no dyspnea and other hypoxia symptoms are observed, and their general condition is good [14].

\section{Severe type [3]}

The disease progresses quickly and meets any of the following conditions:

(1) Significantly increased respiration rate (RR): $R R \geq 60$ / min ( $<2$ months), $R R \geq 50 /$ min ( $2 \sim 12$ months old), $\mathrm{RR} \geq 40 / \mathrm{min}$ ( $1 \sim 5$ years old), $\mathrm{RR} \geq 30 / \mathrm{min}$ ( $>5$ years old), after ruling out the effects of fever and crying [15].

(2) Hypoxia: having assistant respiration chosen from groaning, nasal flaring and three depression sign, cyanosis, and pulse blood oxygen saturation $\left(\mathrm{SpO}_{2}\right) \leq 92 \%$ ( $<90 \%$ in premature infants).

(3) Consciousness disorders: apathy, somnolence, coma, and convulsions.

(4) Food refusal or feeding difficulty and dehydration.

(5) Other manifestations: such as bleeding and coagulation disorders (prolonged prothrombin time and elevated levels of D-dimer), myocardial damage (increased level of myocardial enzymes and troponin, electrocardiogram ST-T changes, cardiomegaly, and cardiac insufficiency in severe cases), gastrointestinal dysfunction, raised level of liver enzyme, and rhabdomyolysis.

5. Critical cases [16]

Disease progresses rapidly to organ failure with any of the following conditions:

(1) Respiratory failure that requires mechanical ventilation: patients present with acute respiratory distress syndrome (ARDS) featured by refractory hypoxemia.
(2) Septic shock: in addition to severe pulmonary infection, SARS-COV-2 can also cause damage and dysfunction of other organs. When dysfunction of the extrapulmonary system, such as circulation, blood, and digestive system, occurs, the possibility of sepsis and septic shock should be considered and the mortality rate increases significantly.

(3) Accompanied by other organ failure that requires intensive care unit (ICU) monitoring and treatment.

\section{Severe and critical clinical warning indicators [3]}

1. Increased breathing rate

2. Poor mental response, lethargy

3. Progressive elevation of lactic acid levels

4. Chest imaging findings indicating bilateral or multi-lobe infiltration, pleural effusion, or rapid progression of conditions during a very short period

5. Infants younger than 3 months or those with existing underlying diseases (e.g., congenital heart disease, bronchopulmonary dysplasia, respiratory tract malformation, abnormal hemoglobin, and severe malnutrition), and immune deficiency or low immunity (long-term use of immunosuppressants)

\section{Auxiliary examinations}

\section{Routine laboratory examinations $[3,11,14]$}

(1) Routine blood test: the total number of white blood cells is normal or decreased, accompanied by lymphocyte reduction; progressive lymphocytopenia might be observed in severe cases. The normal values of children at different ages are different from the adult standards, which should be taken into consideration.

(2) C-reactive protein (CRP): normal or increased.

(3) Erythrocyte sedimentation rate (ESR): elevated in most children.

(4) Procalcitonin (PCT): normal in most cases. A level of PCT $>0.5 \mathrm{ng} / \mathrm{mL}$ indicates coinfection with bacteria.

(5) Others: Elevation of liver enzymes, lactate dehydrogenase, muscle enzymes, and myoglobin; an increased level of D-dimer might be seen in severe cases.

(6) Elevated inflammatory cytokines.

\section{Etiological detection}

Nucleic acid testing is the main method of laboratory diagnosis. SARS-COV-2 nucleic acid can be detected from throat 
swabs (nasopharyngeal swabs are recommended for children), sputum, lower respiratory tract secretions, stool, urine, tears, or blood samples, by real-time quantitative polymerase chain reaction (RT-PCR); or by viral gene sequencing [3]. Nasopharyngeal swab tests are more common in China. The stool sample is as specific as the nasopharyngeal swab [13].

\section{Other methods}

SARS-CoV-2 particles can be isolated from human respiratory epithelial cells through virus culture, but this experiment cannot be carried out in general laboratories [11].

\section{Imaging features [11, 17, 18]}

\section{Chest X-ray examination}

In the early stage of COVID-19, chest images show that the texture of the two lungs increased and became rough, followed by the appearance of small patchy shadows and interstitial changes, especially in the lung periphery. Severe cases can further develop to bilateral multiple ground-glass opacity and pulmonary consolidation, with infrequent pleural effusion.

\section{Chest CT scan}

Pulmonary lesions are shown more clearly by CT, including ground-glass opacity and segmental consolidation in bilateral lungs, especially in the lung periphery. In children with a severe infection, multiple lobar lesions may be present in both lungs. Compared with those in adults, most pediatric patients are mild type whose chest CT characteristics of COVID-19 were atypical, with more localized round glass opacity (GGO) extent, lower GGO attenuation, and relatively rare interlobular septal thickening. In addition, the imaging is required in asymptomatic children with SARS-CoV-2 infection.

\section{Diagnosis $[3,15,19]$}

\section{Suspected cases}

It is necessary to perform a comprehensive analysis based on epidemiological history and clinical manifestations.

\section{Epidemiological history}

(1) Within 14 days before disease onset, children with a travel or residence history in China or a country or region with a serious epidemic where the infection cases was reported.
(2) Within 14 days before disease onset, children with a history of contacting novel coronavirus infected cases (children with positive test for viral nucleic acid).

(3) Within 14 days before disease onset, children with a history of contacting patients with fever or respiratory symptoms who have a travel or residence history in China or a country or region with a serious epidemic where the infection cases was reported.

(4) Children who are related to a cluster outbreak: two or more cases with fever and/or respiratory symptoms occurred within 2 weeks in small areas such as home, office, and school classes.

\section{Clinical features}

(1) Fever and/or respiratory symptoms

(2) With imaging findings of pneumonia caused by SARS$\mathrm{CoV}-2$

(3) In the early phase of the disease, white blood cell counts are normal or decreased, mostly with decreased lymphocyte count and normal or increased CRP

Patients should be suspected of SARS-CoV-2 infection if they meet any one of the criteria in the epidemiological history and any two of the criteria in clinical manifestations. Newborns born to pregnant women with SARS-CoV-2 nucleic acid positive are designated as suspected cases.

Note: Due to the presence of asymptomatic infection that meets the clinical characteristics of (3), no special pneumonia etiological examination, ineffective treatment with oseltamivir and other drugs, and chest X-ray examination consistent with the characteristics of COVID-19, suspected cases should be considered for appropriate etiological examination, even if the child has no clear epidemiological history.

\section{Confirmed case}

Suspected cases become confirmed cases after one of the following etiological or serological evidence:

1. Detection of novel coronavirus nucleic acid is positive by RT-PCR. (Note: rectal swab testing by RT-PCR in children may be more useful than nasopharyngeal swab testing by RT-PCR in determining the effectiveness of treatment and determining the timing of quarantine termination [13].)

2. Viral gene sequencing, being highly homologous with known novel coronaviruses

3. The serum novel coronavirus-specific IgM and IgG antibodies are positive; serum novel coronavirus-specific IgG antibody changes from negative to positive or increased fourfold or higher than that of the acute stage in the recovery stage (Fig. 1) 
Fig. 1 Diagnostic algorithm of COVID-19. Note: (1) Newborns born to pregnant women with SARS-CoV-2 nucleic acid positive are designated as suspected cases. (2) Asymptomatic infection who meets the clinical characteristics of (3), no special pneumonia etiological examination, ineffective treatment with oseltamivir and other drugs, and chest X-ray examination consistent with the characteristics of COVID-19 should be considered as suspected cases, even if the child has no clear epidemiological history

\section{Epidemiological history*:}

1.Within 14 days before disease onset, children with a travel or residence history in China or a country or region with a serious epidemic where the infection cases was reported. 2. Within 14 days before disease onset, children with a history of contacting novel coronavirus infected cases (children with positive test for viral nucleic acid) 3.Within 14 days before disease onset, children with a history of contacting patients with fever or respiratory symptoms who have a travel or residence history in China or a country or region with a serious epidemic where the infection cases was reported.4.Children who are related to a cluster outbreak: Two or more cases with fever and/or respiratory symptoms occurred within 2 weeks in small areas such as home, office, and school classes.

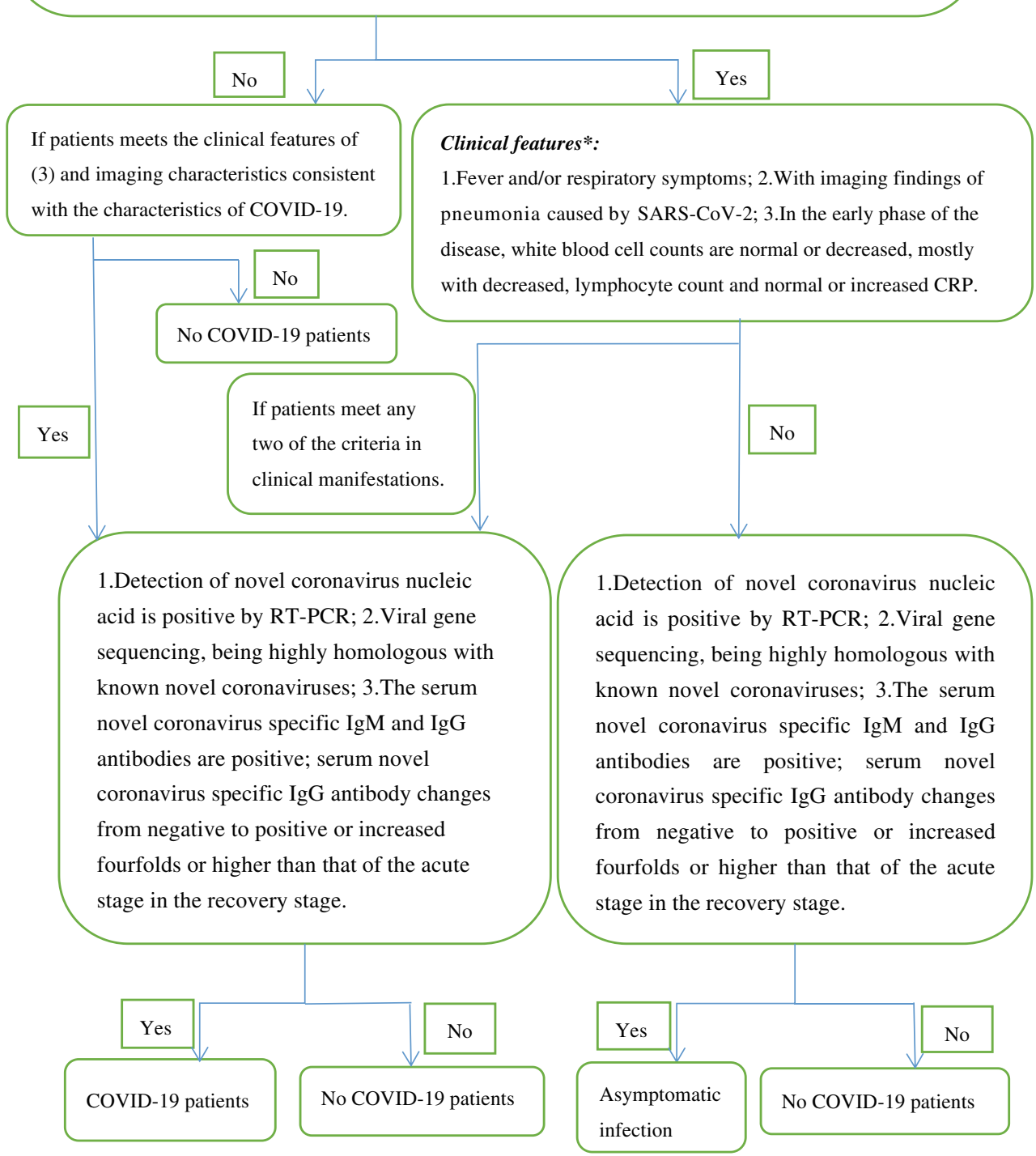

\section{Differential diagnosis}

SARS-CoV-2 infection should be distinguished from adenovirus, influenza virus, respiratory syncytial virus, and mycoplasma pneumonia. In addition, attention should be paid to the identification of human avian influenza virus, parainfluenza virus, human metapneumovirus, human bocavirus, and other viral pneumonia, bacterial pneumonia, fungal pneumonia, legionella, and tuberculosis [19]. It should also be distinguished from non-infectious diseases such as vasculitis, dermatomyositis, and organizing pneumonia [3]. SARS-CoV-2 infection can also be mixed with other bacteria or viruses or have a double infection. Attention should be paid to differential diagnosis and treatment [11]. 
1. Adenovirus pneumonia: The disease is more common in 6 months to 2 years old children, with the appearance of continued high fever, drowsiness and dispirited, pale complexion, severe cough, wheezing, and difficulty breathing. Signs in the lungs appear late, and moist crackles are heard 4 to 5 days after fever onset. Signs of consolidation of the lungs are found after lesion fusion. Blood tests show that the numbers of white blood cells are mostly reduced or normal. Imaging findings show patchy fuzzy shadows or large leaf consolidation [20].

2. Influenza virus pneumonia: There may be persistent high fever, and coughing is obvious. Other symptoms included fatigue, diarrhea, and chest pain. There are small wet moist crackles in the lungs. Routine blood examination shows that the white blood cell count is mostly normal or slightly increased, although some white blood cells are reduced. X-ray manifestations of the chest show irregular flocculent shadows on the lungs on both sides of the hilum, which are not widely distributed [21].

3. Respiratory syncytial virus pneumonia: Children with this infection are usually younger, less than 2 years old, especially below 6 months. Clinical features are prone to wheezing, with or without fever, and wheezing and dyspnea in severe cases. Wheezing sounds and fine moist crackles can be heard upon auscultation. Chest radiographs can show hyperventilation and small patchy shadows. The course of the disease is self-limiting [22].

4. Mycoplasma pneumonia: The disease may occur in any season. Patients are predominantly school-age children; however, the number of cases among younger children is increasing. Infection usually starts with high fever and a cough gradually develops. Lung signs are relatively few. Chest images may reveal manifestations including reticular shadows and small patchy or large consolidation. Routine blood examination shows an increased or normal white blood cell count and CRP is slightly elevated [11].

\section{Case discovery and reporting (isolation measures)}

\section{Case detection, reporting, and isolation $[3,13]$}

During the daily diagnosis and treatment in medical institutions at various levels, upon finding suspected cases that meet the conditions of the disease, an in-hospital specialist or an attending physician consultation should be conducted immediately. If the suspected cases are still considered, the appropriate organization should report directly to the network within $2 \mathrm{~h}$ and collect samples to detect of novel coronavirus nucleic acid as soon as possible. At the same time, the suspected case is immediately transferred to a single person single room in the designated hospital for isolation and treatment under the premise of ensuring the safety of the transfer. The medical staff then implements secondary or higher protection and should pay attention to the strict disinfection disposal of patient excreta and secretions.

When two consecutive rectal swab novel coronavirus nucleic acid tests (the sampling interval is at least $24 \mathrm{~h}$ ) and the specific antibodies IgM and IgG detection of novel coronavirus 7 days after the onset of the disease are still negative in the suspected case, the diagnosis of suspected case can be excluded.

\section{Medical observation [5, 23, 24]}

1. Close contacts or suspected exposures should be subject to medical observation at home or in a single isolated room. The medical observation period is 14 days after the last ineffective protective contact or suspected exposure with a confirmed patient.

2. Newborns delivered by confirmed mothers in China: The child should be separated immediately from the mother for isolation and observation after birth (secondary protection level). There continue to be conflicting data as to the role of breastfeeding on transmitting neonatalmaternal infection. United Nations International Children's Emergency Fund (UNICEF) recommends continuing with breastfeeding, while applying necessary precautions to prevent transmission of infection. In contrast, the Chinese Working Group for the Prevention and Control of Neonatal SARS-CoV-2 Infection recommends milk formula for every child of a mother who has been infected.

(1) Healthy newborns at term: After 1 week of isolation observation in hospital, if the child has a negative test for viral nucleic acid twice, normal feeding, and good general condition, they can be isolated for medical observation at home. If the child develops symptoms at home, they should return to the hospital for examination immediately.

(2) Premature infants or pathological neonates with asphyxia and other diseases should be isolated in a single room and receive appropriate treatment.

(3) Monitoring of SARS-CoV-2 virus nucleic acid: Within $24 \mathrm{~h}, 5-7$ days, and 14 days after birth, respiratory tract secretions are taken for detection of viral nucleic acid. Any positive test for viral nucleic acid should be reported immediately, and the health and disease conditions should be re-evaluated to decide whether the infant can stay at home or be hospitalized for isolation treatment. The treatment method is the same as that for other children. Patients who test negative for virus nucleic acid for the third time can be released from quarantine. 


\section{Treatment}

These patients with asymptomatic infection, mild infection (e.g., fever, cough, and/or myalgias without dyspnea, hypoxia, and tachypnea), and having no underlying condition should only be isolated in the outpatient setting without special treatment. Other patients should be treated with drugs or organ support [25].

\section{Medical isolation}

The four principles of early recognition, early isolation, early diagnosis, and early treatment should be emphasized. Medical isolation is supposed to be carried out once the suspected cases are identified. Suspected and confirmed cases should be admitted to designated hospitals. Suspected case should be isolated in a single room, while confirmed cases can be arranged in the same room [11].

\section{General treatment}

The general therapeutic strategies include bed rest; monitoring vital signs; strengthening supportive treatment; ensuring sufficient calories; maintaining homeostasis such as water, electrolytes, and acid-base balance; and maintaining an unobstructed respiratory tract. Older children should be supported using psychotherapy.

\section{Oxygen therapy}

Patients with hypoxemia $\left(\mathrm{SpO}_{2}<95 \%\right)$ should receive oxygen therapy, including nasal catheter and mask oxygen, and whether respiratory distress and/or hypoxemia are alleviated should be assessed promptly. Tracheal Intubation and noninvasive or invasive mechanical ventilation should be undertaken for patients with severe disease instantly [8, 26, 27].

\section{Antiviral treatment}

There are currently no effective antiviral drugs to treat COVID-19 for children (Table 1).

\section{Interferon- $a$}

Interferon can inhibit virus replication in a variety of ways. In the early stage of infection, interferon can reduce the viral load, which can help to alleviate symptoms and shorten the course of the disease. However, coronavirus infections cannot be targeted. Interferon- $\alpha$ atomization can be tried, such as 200,000 to $400,000 \mathrm{IU} / \mathrm{kg}$ or 2 to $4 \mu \mathrm{g} / \mathrm{kg}$ in $2 \mathrm{~mL}$ sterile water, with nebulization two times per day for 5-7 days [26]. However, the drug increases the risk of fever, headache, nausea, vomiting, lack of concentration, and even pessimism.
Lopinavir/litonavir

Lopinavir, which is a protease inhibitor of human immunodeficiency virus 1(HIV-1), is commonly used in combination with ritonavir, which increases the half-life of lopinavir by inhibiting cytochrome P450. Ex vivo experiments indicated that lopinavir/ritonavir could inhibit coronavirus replication to a certain extent [28]. Attempts have been made to use this drug to treat adult patients with pneumonia caused by SARS-CoV-2 [29]. A recently published systematic review revealed that the effect of this drug combination is mainly manifested in its early application, which can reduce patient mortality and glucocorticoid dosage. However, if the early treatment window is missed, late application has no significant effect. The use of lopinavir/litonavir in children should be undertaken with caution, and children with severe disease can be considered as appropriate. It is recommended that the usage and dosage of lopinavir/ritonavir in children can refer to the guidelines for anti-HIV therapy. The recommended doses: weight $7-15 \mathrm{~kg}, 12 \mathrm{mg} / 3 \mathrm{mg} / \mathrm{kg}$; weight $15-40 \mathrm{~kg}, 10 \mathrm{mg} /$ $2.5 \mathrm{mg} / \mathrm{kg}$; weight $>40 \mathrm{~kg}, 400 \mathrm{mg} / 100 \mathrm{mg}$ as adult each time, twice a day for 1-2 weeks. Please pay attention to the possible side effects such as diarrhea and nausea and vomiting during use. Children with liver disease should contraindicate this drug $[11,27]$.

\section{Ribavirin}

Ribavirin, as a broad-spectrum potent antiviral drug, belongs to the group of drugs acting on the synthesis of nucleosides, which have inhibitory effects on many DNA and RNA viruses [30]. However, in vitro experiments showed that high doses of ribavirin have inhibitory effects on coronaviruses. It is recommended to use it in combination with interferon- $\alpha$ or lopinavir/ritonavir, at $10 \mathrm{mg} / \mathrm{kg} / \mathrm{time}$, via intravenous infusion, 2 to 3 times daily [14]. A critically ill child can be given antiviral therapy with ribavirin injection empirically, at $15 \mathrm{mg} / \mathrm{kg}$ each time, twice a day, and the course of treatment should not exceed 5 days [31]. At the same time, in view of the side effects of ribavarin, including the teratogenic and hemolytic anemia, it should be used with caution in pregnant women and children.

\section{Remdesivir}

Remdesivir, a new generation of ribavirin agents, is a nucleoside analog that can integrate into the nascent viral RNA strand and lead to premature termination of viral replication $[32,33]$. However, unlike ribavirin, it has strong antiviral activity in vitro against human infection with coronaviruses and various bat-derived coronaviruses [32]. In addition, its efficacy is better than that of lopinavir/litonavir combined with interferon-beta [34]. There are currently reports of its effective 
Table 1 Antiviral drugs of COVID-19

\begin{tabular}{|c|c|c|c|}
\hline Antiviral drugs & Dosage & Indications & Side effects \\
\hline Interferon $\alpha$ & $\begin{array}{l}200,000 \text { to } 400,000 \mathrm{IU} / \mathrm{kg} \text { in } 2 \mathrm{~mL} \text { sterile } \\
\text { water, with nebulization two times per day } \\
\text { for } 5-7 \text { days }\end{array}$ & $\begin{array}{l}\text { Covid-19, chronic hepatitis B and C } \\
\text { patients, etc. }\end{array}$ & $\begin{array}{l}\text { Fever, headache, nausea, } \\
\text { vomiting, lack of } \\
\text { concentration, and even } \\
\text { pessimism }\end{array}$ \\
\hline Lopinavir/litonavir & $\begin{array}{l}\text { Weight } 7-15 \mathrm{~kg}, 12 \mathrm{mg} / 3 \mathrm{mg} / \mathrm{kg} \text {; weight } \\
15-40 \mathrm{~kg}, 400 \mathrm{mg} / 100 \mathrm{mg} \text { as adult each } \\
\text { time, twice a day for } 1-2 \text { weeks }\end{array}$ & COVID-19 and HIV patients & Diarrhea, nausea and vomiting \\
\hline Ribavirin & $\begin{array}{l}10 \mathrm{mg} / \mathrm{kg} / \text { time, via intravenous infusion, } 2 \text { to } \\
3 \text { times daily }\end{array}$ & $\begin{array}{l}\text { COVID-19 patients, viral } \\
\text { pneumonia, and bronchitis } \\
\text { caused by respiratory syncytial } \\
\text { virus }\end{array}$ & $\begin{array}{l}\text { Teratogenic and hemolytic } \\
\text { anemia }\end{array}$ \\
\hline Remdesivir & - & COVID-19 patients & $\begin{array}{l}\text { Skin rash, diarrhea, and renal } \\
\text { dysfunction }\end{array}$ \\
\hline Favipiravir & - & COVID-19 patients & $\begin{array}{l}\text { Skeletal muscle atrophy and } \\
\text { myocardial necrosis }\end{array}$ \\
\hline $\begin{array}{l}\text { Chloroquin } \\
\text { phosphate/Hydroxychloroq- } \\
\text { uine }\end{array}$ & $\begin{array}{l}\text { 3-5 mg/kg/day (max dose } 400 \mathrm{mg} \text { ) } \\
\text { hydroxychloroquine sulfate iv, twice daily } \\
\text { for } 5 \text { days }\end{array}$ & COVID-19 and malaria patients & $\begin{array}{l}\text { QT interval prolongation, } \\
\text { ventricular arrhythmias and } \\
\text { other cardiac toxicity }\end{array}$ \\
\hline
\end{tabular}

use in related treatment; however, further clinical validation is needed [33]. However, the patients who take the medicine have the risk of skin rash, diarrhea, and renal dysfunction. In severe cases, septic shock, acute renal injury, multiple organ dysfunction syndrome, and other side effects may also occur.

\section{Favipiravir}

Favipiravir (FPV) is an RNA-dependent RNA polymerase inhibitor. It has now been shown to be useful against SARSCoV-2 in initial clinical trials. Some studies have found that compared to Lopinavir/Ritonavir, the FPV-treated patient demonstrated much better therapeutic response especially with regard to faster viral clearance and improvement rate in chest imaging [35]. At present, there is no specific dosing recommendation for FPV in pediatric COVID-19 patients [25]. But we should be alert to the possibility of skeletal muscle atrophy and myocardial necrosis.

\section{Chloroquin phosphate}

The use of chloroquine phosphate for antiviral therapy has been added to the Diagnosis and Treatment of Pneumonia Caused by 2019- nCoV (trial version 6) [36]. Chloroquine phosphate has been confirmed to be resistant to a variety of viruses in vitro. This drug has multiple activities, one of which is to alkalize the phagolysosome, which hampers the low-pHdependent steps of viral replication [37]. Studies have found that chloroquine, at an $\mathrm{EC}_{50}$ of $1.1 \mu \mathrm{M}$, is effective in preventing replication of this novel coronavirus [38]. But there are in vitro studies that show hydroxychloroquine appears to be more potent [39]. Some experts from Iran suggested to use $3-5 \mathrm{mg} / \mathrm{kg} /$ day (max dose $400 \mathrm{mg}$ ) hydroxychloroquine sulfate iv, in pediatric patients, twice daily for 5 days [25]. However, the drug has been independently shown to increase the risk for QT interval prolongation, ventricular arrhythmias, and other cardiac toxicity [40].

\section{Other drugs}

Antibacterial agents The blind or irrational use of antimicrobials, especially in combination with broad-spectrum antimicrobials, should be avoided. Close attention should be paid to changes in the condition of children with bacterial or fungal coinfection; samples should be collected actively for pathogen analysis and the timely or rational use of antibiotics or antifungal drugs [41, 42].

Arbidol, oseltamivir, and other anti-influenza drugs Arbidol is administrated for adults infected with SARS-CoV-2; however, its efficacy and safety remain unclear. Oseltamivir and other anti-influenza agents can be applied in patients coinfected with other influenza viruses [43, 44].

Glucocorticoids When using glucocorticoids, it is necessary to strictly monitor the indications, combined with the severity of the disease, and comprehensively consider the following indicators: Fever over $38.5^{\circ} \mathrm{C}$ for 3 days, $\mathrm{CRP} \geq 30 \mathrm{mg} / \mathrm{L}$, serum ferritin $\geq$ $1000 \mu \mathrm{g} / \mathrm{kg}$, the rapid progressing of imaging findings, significant hypoxia, patients manifesting the symptoms of ARDS, and obvious wheezing. Methylprednisolone can be used for short periods (3-5 days). The recommended dose of methylprednisolone should not exceed 1-2 mg/kg/day [8, 27, 44]. 
Gamma globulin for injection For severe and critical cases, of the use gamma globulin can be considered; however, its efficacy remains unclear at present. The recommended dose is $1.0 \mathrm{~g} / \mathrm{kg} /$ day for 2 days, or $400 \mathrm{mg} / \mathrm{kg} /$ day for 5 days $[11,44]$.

Convalescent plasma Blood transfusion therapy (anti-serum) of convalescent patients can be considered for severe and critically ill patients [3]. However, the collection of convalescent plasma must be conducted at the appropriate time to ensure that it has a high neutralizing antibody titer, so as to significantly improve the survival rate of patients [10].

Immunotherapy For adults with extensive lesions of both lungs, severely ill patients, and for those with laboratory tests showing elevated interleukin (IL)-6 levels, tocilizumab treatment can be tried. When using this drug, attention should be paid to allergic reactions, and people with active infection such as tuberculosis are contraindicated [3]. The efficacy and safety of this drug in children remains to be determined; therefore, it should be used caution.

Vaccines Vaccines have the effect of preventing infection, reducing disease severity, and viral shedding. The main antigens for vaccine development are the structural spike glycoprotein $\mathrm{S}$ or its receptor-binding domain (RBD). Several vaccines against SARS-CoV-2 are in development, including the classical inactivated and attenuated vaccines, the protein subunit and virus-like particle vaccines (VLP), viral vector-based vaccines, as well as the newer DNA- and RNA-based vaccines. So far, some vaccines has entered into clinical trials, such as mRNA-1273 vaccine, Ad5-nCoV, etc. [35, 45].

\section{Treatment of patients with severe and critical disease}

Basic principles On the basis of symptomatic treatment, these measures, including treatment of underlying diseases, active comprehensive treatment to correct hypoxemia, the provision of effective organ function protection, and preventing disease complications need to be implemented.

\section{Respiratory support}

1. Severely ill children should use a nasal cannula or simple continuous positive airway pressure (CPAP) to inhale oxygen. CPAP generally has a pressure of 5-10 $\mathrm{cmH}_{2} \mathrm{O}$. When refractory hypoxemia or ARDS (according to the latest PARDS diagnostic criteria in 2015 [46]) occurs, it is critical that timely blood gas analysis and assessment of the condition are performed. The patient in critical condition should be transferred to the pediatric intensive care unit (PICU) in time to adjust the oxygen therapy plan, including high-flow nasal cannula oxygen therapy or non-invasive mechanical ventilation. If hypoxia symptoms cannot be corrected within 1 to $2 \mathrm{~h}$, invasive mechanical ventilation should be performed [36, 44]. For children with respiratory failure and/or circulatory failure that cannot be improved after the above treatment, the use of extracorporeal membrane oxygenation (ECMO) can be considered [3, 11, 36].

2. Invasive mechanical ventilation strategy: $\mathrm{PaO}_{2}$ is maintained at $55 \sim 80 \mathrm{mmHg}$ or $\mathrm{SpO}_{2}$ at 88 to $95 \%$. The lung protective ventilation strategy is adopted, in which small tidal volume ventilation for 3 to $8 \mathrm{~mL} / \mathrm{kg}$ is provided and the plateau pressure is $28 \mathrm{cmH}_{2} \mathrm{O}$ on the inhale. The level of plateau pressure can increase to $29 \sim 32 \mathrm{cmH}_{2} \mathrm{O}$ for children with reduced chest wall compliance. The best positive end-expiratory pressure (PEEP) can be selected according to the PEEP-FiO 2 table method. Patients with moderate to severe ARDS can use a higher PEEP ( $>12$ $\mathrm{cmH}_{2} \mathrm{O}$ ) in the early stage. For children with severe ARDS, it is recommended to perform lung recruitment, adjust the positive airway pressure to $30 \sim 45 \mathrm{cmH}_{2} \mathrm{O}$ for $30 \sim 40 \mathrm{~s}$, and set the inspiratory pressure at $40 \mathrm{cmH}_{2} \mathrm{O}$ for $40 \mathrm{~s}$. It is recommended that prone position ventilation is provided for more than $12 \mathrm{~h}$ every day $[3,19]$. But it is important to note that the hemodynamics are stable.

3. Indications for ECMO: No improvement after mechanical ventilation and other treatment methods, progressive deterioration of the $\mathrm{P} / \mathrm{F}$ or oxygen index $(\mathrm{OI}), \mathrm{PaO}_{2} / \mathrm{FiO}_{2}<$ $60 \mathrm{mmHg}$ or $\mathrm{OI}>35$ for more than $6 \mathrm{~h}$, or severe respiratory acidosis $(\mathrm{pH}<7.15)$, circulation function that cannot be improved, basal blood pressure maintained by a large number of vasoactive drugs, or continuously elevated blood lactic acid levels, and other conditions [11]. When the underlying disease is controlled and the cardiopulmonary function shows signs of recovery, withdrawal of the machine test can be started [3].

4. Sedative muscle relaxation and artificial hibernation therapy: Patients undergoing mechanical ventilation or receiving ECMO need to be sedated using analgesia. For patients who are very resistant during the establishment of an artificial airway, short-term application of low-dose muscle relaxants is recommended. Hibernation therapy is recommended for patients with severe disease and a low oxygenation index. Artificial hibernation therapy can reduce the body's metabolism and oxygen consumption, while simultaneously dilated the pulmonary blood vessels to significantly improve oxygenation. It is recommended to supply a continuous intravenous bolus, and closely monitor the patient's blood pressure. To prevent the occurrence and exacerbation of lung infections, we should try to avoid prolonged excessive sedation, and withdraw muscle relaxants as soon as possible when conditions permit. It is recommended to closely monitor the depth of sedation [31]. 


\section{Circulatory support}

Consciousness, skin condition, pulse, capillary filling time, urine volume, and blood lactic acid levels should be closely observed to identify shock early. If the heart function is normal, the septic shock procedure can be followed. If ARDS is present, strict fluid management should be performed to ensure tissue perfusion to maintain a negative liquid balance, and to actively treat capillary leakage and maintain heart and kidney function. Hemodynamics need to be closely monitored during anti-shock therapy $[3,44]$.

\section{Other organ function support}

Organ function support is used to closely monitor the organ functions of children, including the nervous system, digestive system, urinary system, blood system, coagulation function, water-electrolyte acid-base balance, endocrine internal environment, and others, and then provide corresponding treatment.

\section{Blood purification}

Blood purification can clear inflammatory factors and block the "cytokine storm," thereby relieving the damage caused by inflammatory responses to the body. It can be used to treat mid to early cytokine storms in severe and critically ill patients [3]. When multiple organ failure (especially acute kidney injury) is involved, or when capacity overload and life-threatening water, electrolyte, or acid-base imbalances are considered, continuous blood purification treatment should be considered [11]. If combined with liver failure, plasma exchange is feasible [47].

\section{Psychotherapy $[26,44]$}

We must integrate families, schools, and psychologists to provide children with comprehensive psychological and life support.

\section{Children who have been isolated}

During this period, children are prone to fear, anxiety, depression, and insomnia [48]. The main intervention measures are:

(1) Provide basic living and treatment security for the isolation of sick children.

(2) Provide psychological support outside the medical care team for the isolated children, encourage children more, and give children companionship outside medical operation hours.

(3) Assist in communicating with parents and transmitting information, such as video calls, and timely transmission of classmates' support information.
(4) Explain the importance and necessity of isolation and encourage children to build confidence that they will recover their health as soon as possible.

\section{Healthy children whose parents or guardians are passively isolated due to illness}

Children have a number of worries and anxieties about their parents' health, their parents leaving, loneliness, and being abandoned. Anxiety, depression, and even post-traumatic stress disorder can occur in severe cases. The main interventions are:

(1) According to the children's age-related cognition level, different notification methods are used to let them know why they are separated from their parents, such that children realize that their parents are sick and need treatment, rather than abandoning them.

(2) Provide suitable living places, strengthen communication with other relatives, and set up relatively stable care team members as far as possible.

(3) Assist in communicating with parents who are physically fit in isolation to ease anxiety caused by separation.

(4) Continue to follow a regular routine.

(5) Consult the psychiatric department if necessary.

\section{Remove isolation and discharge standards [3, $36,44,49]$}

The body temperature of the confirmed cases returned to normal for more than 3 days. The respiratory symptoms improved significantly, and the pulmonary imaging showed obvious absorption of inflammation. The nucleic acid test for respiratory pathogens was negative at two consecutive time points (with a sampling interval of at least $24 \mathrm{~h}$ ). If these conditions are met, patients can discharge from isolation or transferred to the appropriate department for treatment of other diseases according to their condition.

\section{Precautionary measures $[11,26,44]$}

On the one hand, it is necessary to control the source of infection, and children infected by novel coronavirus should be isolated at home or admitted to designated hospitals under the guidance of medical staff. On the other hand, it is necessary to block the transmission routes, prevent respiratory tract or contact transmission, reduce exposure to infection, and avoid going to public places. In addition, it is necessary to 
protect vulnerable groups, eat a balanced diet, exercise adequately, and rest regularly.

Acknowledgments We thank all authors for sharing the critical information and literature searching, and their hard work for the included evidences in this guideline. Since December 2019, a novel coronavirusinfected pneumonia epidemic has emerged in Wuhan, Hubei province, China. With the spread of the epidemic, such cases have also been found in other parts of China and in many foreign countries. Initially called 2019 novel coronavirus (2019-nCoV), it was later named coronavirus disease 2019 (COVID-19) and severe acute respiratory syndrome coronavirus 2 (SARS-CoV-2) [47, 50]. Our deepening understanding of the clinical manifestations, pathology, and the accumulation of diagnosis and treatment experience of the disease, has further strengthened the early diagnosis and treatment of the disease, reduced the mortality rate, prevented nosocomial infection as much as possible, and better guide the treatment of children with novel coronavirus infection/pneumonia. In these circumstances, experts can refer to the Diagnosis and Treatment of Pneumonia Caused by 2019- $n \mathrm{CoV}$ (trial version 7) issued by the National Health Commission, Guidelines for the clinical management of severe acute respiratory infection (SARS) caused by suspected novel coronavirus infection of world health organization (WHO) and the diagnosis and treatment strategies of pediatric-related viral infections. They can also combine the characteristics of confirmed cases of children with clinical diagnosis and treatment experience of adult patients reported in China, allowing them to put forward recommendations for the diagnosis and treatment of novel coronavirus infections in children for reference by pediatricians.

Authors' contributions Hongjun Miao, Han Li, and Yinying Yao: performed the literature search and data analysis, and wrote the paper; Mingfu Wu, Chao Lu, Jun Wang, Man Tian, Ying Li, Peiliang Luo, Jianhui Gu, Bin Yuan, Shouchuan Wang, and Xia Zhao: helped with the review and writing of the paper; Weihua Gan and Deyu Zhao: conceived and designed the structure and framework of this review, and critically revised the work.

Availability of data and material Data sharing not applicable to this article as no datasets were generated or analyzed during the current study.

\section{Compliance with ethical standards}

Conflict of interest The authors declare that they have no conflict of interest.

Ethics approval Not applicable.

Consent Not applicable.

\section{Code availability Not applicable.}

Open Access This article is licensed under a Creative Commons Attribution 4.0 International License, which permits use, sharing, adaptation, distribution and reproduction in any medium or format, as long as you give appropriate credit to the original author(s) and the source, provide a link to the Creative Commons licence, and indicate if changes were made. The images or other third party material in this article are included in the article's Creative Commons licence, unless indicated otherwise in a credit line to the material. If material is not included in the article's Creative Commons licence and your intended use is not permitted by statutory regulation or exceeds the permitted use, you will need to obtain permission directly from the copyright holder. To view a copy of this licence, visit http://creativecommons.org/licenses/by/4.0/.

\section{References}

1. Li Q, Guan X, Wu P et al (2020) Early transmission dynamics in Wuhan, China, of novel coronavirus-infected pneumonia. N Engl J Med. https://doi.org/10.1056/NEJMoa2001316

2. Guan WJ, Ni ZY, Hu Y et al (2020) Clinical characteristics of coronavirus disease 2019 in China. N Engl J Med. https://doi.org/ 10.1056/NEJMoa2002032

3. National Health Commission of the People's Republic of China (2020) Diagnosis and treatment of pneumonia caused by 2019nCoV (trial version7). http://health.people.com.cn/n1/2020/0304/ c14739-31616706.html?from=singlemessage \&isappinstalled $=0$. Access 4 March 2020

4. Wei M, Yuan J, Liu Y et al (2020) Novel coronavirus infection in hospitalized infants under 1 year of age in Chinas. JAMA. https:// doi.org/10.1001/jama.2020.2131

5. Castagnoli R, Votto M, Licari A et al (2020) Severe acute respiratory syndrome. Coronavirus 2 (SARS-CoV-2) infection in children and adolescents. JAMA Pediatrics. https://doi.org/10.1001/ jamapediatrics.2020.1467

6. Zhao Y, Zhao ZX, Wang YJ, et al (2020). Single-cell RNA expression profiling of ACE2, the putative receptor of Wuhan 2019-nCov [published online January 26, 2020]. bioRxiv. https://doi.org/10. 1101/2020.01.26.919985

7. Wrapp D, Wang N, Corbett KS et al (2020) Cryo-EM structure of the 2019-nCoV spike in the prefusion conformation. bioRxiv. https://doi.org/10.1101/2020.02.11.944462

8. Fang F, Luo XP (2020) Facing the pandemic of 2019 novel coronavirus infections: the pediatric perspectives. Zhonghua Er Ke Za Zhi 58(2):81-85. https://doi.org/10.3760/cma.j.issn.0578-1310. 2020.02.001 (in Chinese)

9. Huang C, Wang Y, Li X et al (2020) Clinical features of patients infected with 2019 novel coronavirus in Wuhan, China. Lancet 395(10223):497-506. https://doi.org/10.1016/S0140-6736(20) 30183-5

10. Wang D, Hu B, Hu C et al (2020) Clinical characteristics of 138 hospitalized patients with 2019 novel coronavirus-infected pneumonia in Wuhan. China JAMA. https://doi.org/10.1001/jama. 2020.1585

11. National Children's Health and Disease Clinical Medical Research Center, National Children's Regional Medical Center, Children's Hospital Affiliated to Zhejiang University School of Medicine (2020) Guidelines for diagnosis and treatment of pneumonia Caused by 2019- $\mathrm{nCoV}$ in children. (Trial version 1). news.66wz. com/system/2020/02/01/105229715.shtml. Access 1 February 2020

12. She JT, Liu LQ, Liu WJ (2020) COVID-19 epidemic: disease characteristics in children. J Med Virol. https://doi.org/10.1002/jmv. 25807

13. Xu Y, Li XF, Zhu B et al (2020) Characteristics of pediatric SARSCoV-2 infection and. Potential evidence for persistent fecal viral shedding. Nat Med 26(4):502-505. https://doi.org/10.1038/ s41591-020-0817-4

14. Expert Group for Diagnosis and Treatment of 2019-nCoV Infection in Children's Hospital of Chongqing Medical University, Xu HM, Luo ZX, Xu F (2020) Diagnosis and treatment of novel coronavirus infection in Children (Children's Hospital of Chongqing Medical University trial version 2)[J/OL].Journal of Pediatric Pharmacy. http://kns.cnki.net/kcms/detail/50.1156.R.20200226.1309.002. html. Access 27 Feb 2020

15. Shen KL, Yang YH, Jiang RM et al (2020) Updated diagnosis, treatment and prevention of COVID-19 in children: experts' consensus statement (condensed version of the second edition). World $\mathrm{J}$ Pediatr:1-8. https://doi.org/10.1007/s12519-020-00362-4 Online ahead of print 
16. Chen ZM, Fu JF, Shu Q et al (2020) Diagnosis and treatment recommendations for pediatric respiratory infection caused by the 2019 novel coronavirus. World J Pediatr. https://doi.org/10.1007/ s12519-020-00345-5

17. Chen N, Zhou M, Dong X et al (2020) Epidemiological and clinical characteristics of 99 cases of 2019 novel coronavirus pneumonia in Wuhan, China: a descriptive study. Lancet. 395(10223):507-513. https://doi.org/10.1016/S0140-6736(20)30211-7

18. Duan Y, Zhu Y, Tang L et al (2020) CT features of novel coronavirus pneumonia (COVID-19) in children. Eur Radiol. https://doi. org/10.1007/s00330-020-06860-3

19. Pediatric Branch of Hubei Medical Association; Pediatric Branch of Wuhan Medical Association; Pediatric Medical Quality Control Center of Hubei (2020) Recommendation for the diagnosis and treatment of novel coronavirus infection in children in Hubei (trial version 1). Chin J Contemp Pediatr 22(2):96-99. https://doi.org/10. 7499/j.issn.1008-8830.2020.02.003 (in Chinese)

20. Lin J, Chen Z et al (2019) Research progress on early identification of severe adenovirus pneumonia in children. Zhejiang Da Xue Xue Bao Yi Xue Ban 48(5):567-572

21. Wang H, Wei R, Rao G et al (2020) Characteristic CT findings distinguishing 2019. Novel coronavirus disease (COVID-19) from influenza pneumonia. Eur Radiol. https://doi.org/10.1007/s00330020-06880-Z

22. Li H, Chen K, Liu M et al (2020) The profile of peripheral blood. lymphocyte subsets and serum cytokines in children with 2019 novel coronavirus pneumonia. J Infect. https://doi.org/10.1016/j. jinf.2020.04.001

23. Yang J, Piao MH, Xia SW et al (2020) Proposed prevention and control of 2019 novel coronavirus infection in neonates. Chin J Perinat Med 23(2):80-84. https://doi.org/10.3760/cma.j.issn.10079408.2020.02.002 (in Chinese)

24. Zhou WH, Feng X, Mu DZ et al (2020) Expert advice on the workflow of respiratory virus infection management in neonatal period. Chin J Evid Based Pediatr 15(1):5-9. https://doi.org/10. 3969/j.issn.1673-5501.2020.01.000 (in Chinese)

25. Tezer H, Demirdağ B (2020) Novel coronavirus disease (COVID19) in children. Turk J Med Sci 50(SI-1):592-603. https://doi.org/ 10.3906/sag-2004-174

26. Shen K, Yang Y, Wang T et al (2020) Diagnosis, treatment, and prevention of 2019 novel coronavirus infection in children: experts' consensus statement. World J Pediatr. https://doi.org/10.1007/ s12519-020-00343-7

27. Xu KJ, Cai HL, Shen YH et al (2020) Management of corona virus disease-19 (COVID-19): the Zhejiang experience. J Zhejiang Univ (Med Sci) 49(1):0. https://doi.org/10.3785/j.issn.1008-9292.2020. 02.02 (in Chinese)

28. Chan JF, Yao Y, Yeung ML et al (2015) Treatment with lopinavir/ ritonavir or interferon-betalb improves outcome of MERS-CoV infection in a nonhuman primate model of common marmoset. $\mathrm{J}$ Infect Dis 212:1904-1913. https://doi.org/10.1093/infdis/jiv392

29. National Health Commission of the People's Republic of China. (2020). Diagnosis and Treatment of Pneumonia Caused by 2019nCoV(trial version 4 ). http://www.nhc.gov.cn/xcs/zhengcwj/ 202001/4294563ed35b43209b31739bd0785e67/files/ 7a9309111267475a99d4306962c8bf78.pdf. Access 28 January 2020

30. Wang Y, Fan G, Salam A et al (2019) Comparative effectiveness of combined favipiravir and oseltamivir therapy versus oseltamivir monotherapy in critically ill patients with influenza virus infection. J Infect Dis https://doi.org/10.1093/infdis/jiz656

31. Shanghai novel coronavirus Disease Clinical Treatment Expert Group (2020) Expert consensus on comprehensive treatment of 2019 novel coronavirus disease in Shanghai. Chin J Infect Dis. https://doi.org/10.3760/cma.j.issn.1000-6680.2020.0016 [Network prepublication] (in Chinese)
32. Li H, Wang YM, Xu JY et al (2020) Potential antiviral therapeutics for 2019 Novel coronavirus. Zhonghua Jie He He Hu Xi Za Zhi 43(0):E002. https://doi.org/10.3760/cma.j.issn.1001-0939.2020. 0002 (in Chinese)

33. Wang M, Cao R, Zhang L et al (2020) Remdesivir and chloroquine effectively inhibit the recently emerged novel coronavirus (2019nCoV) in vitro. Cell Res 30(3):269-271. https://doi.org/10.1038/ s41422-020-0282-0

34. Lu H (2020) Drug treatment options for the 2019-new coronavirus(2019-nCoV). Biosci Trends. https://doi.org/10.5582/bst.2020. 01020

35. Uddin M, Mustafa F, Rizvi TA et al (2020) SARS-CoV-2/COVID19: viral genomics, epidemiology, vaccines, and therapeutic interventions. Viruses 12(5):E526. https://doi.org/10.3390/v12050526

36. National Health Commission of the People's Republic of China (2020) Diagnosis and Treatment of Pneumonia Caused by 2019nCoV (trial version 6). http://www.nhc.gov.cn/yzygj/s7653p/ 202002/8334a8326dd94d329df351d7da8aefc2/files/ b218cfeb1bc54639af227f922bf6b817.pdf. Access 19 February 2020

37. Rolain JM, Colson P, Raoult D (2007) Recycling of chloroquine and its hydroxyl analogue to face bacterial, fungal and viral infections in the 21st century. Int J Antimicrob Agents 30:297-308. https://doi.org/10.1016/j.ijantimicag.2007.05.015

38. Colson P, Rolain JM, Raoult D (2020) Chloroquine for the 2019 novel coronavirus. Int J Antimicrob Agents 105923. https://doi.org/ 10.1016/j.ijantimicag.2020.105923

39. Yao X, Ye F, Zhang M et al (2020) In vitro antiviral activity and projection of optimized dosing design of hydroxychloroquine for the treatment of severe acute respiratory syndrome coronavirus 2 (SARS-CoV-2). Clin Infect Dis. https://doi.org/10.1093/cid/ ciaa237

40. Simsek Yavuz S, Ünal S (2020) Antiviral treatment of COVID-19. Turk J Med Sci 50(SI-1):611-619. https://doi.org/10.3906/sag2004-145

41. National Health Commission of People's Republic of China (2020) Diagnosis and treatment of pneumonia caused by novel coronavirus (trial version 4). https://www.nhc.gov.cn/xcs/zhengcwj/202001/ 4294563 ed 35 b 43209 b 31739 bd 0785 e 67 /files/ 7 a9309111267475a99d4306962c8bf78.pdf. Access 28 January 2020

42. National Health Commission of People's Republic of China (2020) Code for the diagnosis and treatment of community-acquired pneumonia in children (2019 edition). https:/www.nhc.gov.cn/yzygj/ s7653/201902/bfa758ad6add48a599bc74b588a6e89a.shtml. Access 11 February 2019

43. National Health Commission of People's Republic of China (2020) Influenza diagnosis and treatment protocol (revised edition 2019). $\mathrm{h} \mathrm{t} \mathrm{tps://wenku.baidu.com/vi} \mathrm{e} \mathrm{w} \mathrm{/} 00$ f $0 \mathrm{~d} 41$ d2079168884868762caaedd3383c4b57f.html. Access 30 November 2019

44. Jiang Y, Xu BP, Jin RM et al (2020) Expert consensus on diagnosis, treatment, and prevention of 2019 novel coronavirus infection in children (version 4). Chin J Appl Clin Pediatr 35(2):81-85. https:// doi.org/10.3760/cma.j.issn.2095-428x.2020.02.001 (in Chinese)

45. Zimmermann P, Curtis N (2020) Coronavirus infections in children including COVID-19: an overview of the epidemiology, clinical features, diagnosis, treatment and prevention options in children. Pediatr Infect Dis J 39(5):355-368. https://doi.org/10.1097/INF. 0000000000002660

46. Xu F, Wang F, Qian SY et al (2016) Interpretation of 2015 pediatric acute respiratory distress syndrome: consensus recommendations from the pediatric acute lung injury consensus conference. Zhonghua Er Ke Za Zhi 54(5):323-326. https://doi.org/10.3760/ cma.j.issn.0578-1310.2016.05.003 
47. World Health Organization (2020) WHO director-general's remarks at the media briefing on 2019-nCoV on 11 February 2020. https:// www.who.int/dg/speeches/detail/who-director-general-s-remarksat-the-media-briefing-on-2019-ncov-on-11-february-2020. Accessed 11 February 2020

48. Jiao WY, Wang LN, Liu J et al (2020) Behavioral and emotional disorders in children during the COVID-19 epidemic. J Pediatr. https://doi.org/10.1016/j.jpeds.2020.03.013

49. National Health Commission of the People's Republic of China (2020) Diagnosis and Treatment of Pneumonia Caused by 2019nCoV(version 5). http://www.nhc.gov.cn/yzygj/s7653p/202002/ 3b09b894ac9b4204a79db5b8912d4440.shtml. Access 5 February 2020

50. Gorbalenya AE, Baker SC, Baric RS, et al Severe acute respiratory syndrome-related coronavirus - the species and its viruses, a statement of the Coronavirus Study Group. bioRxiv: 2020.02.07.937862

Publisher's note Springer Nature remains neutral with regard to jurisdictional claims in published maps and institutional affiliations. 